\title{
Pengembangan Variasi Latihan Ladder Drill Pada Peserta Ekstrakurikuler Sepakbola Semester Ganjil SDN 1 Cluring Tahun Ajaran 2018/2019
}

\author{
Jefri Setya Pradana', Galih Farhanto², Wawan Setiawan ${ }^{3}$ \\ 1,2,3Fakultas Olahraga dan Kesehatan \\ 1,2,3Universitas PGRI Banyuwangi \\ Email: jefrisport@yahoo.com
}

\begin{abstract}
ABSTRAK
Model latihan sangat dibutuhkan oleh beberapa cabang olahraga dalam meningkatkan keterampilan atletnya. Pengembangan model latihan harus dilakukan oleh para pelatih olahraga kepada atlet agar dapat bisa bersaing dalam pertandingan yang diikuti. Penelitian ini adalah penelitian pengembangan yaitu variasi latihan ladder drill. Subyek penelitian adalah peserta ekstrakurikuler SDN 1 Cluring Kabupaten Banyuwangi. Hasil penelitian menunjukkan bahwa Tingkat kelayakan Variasi Latihan Ladder Drill pada peserta ekstrakurikuler sepakbola tingkat sekolah dasar ini sebesar $96 \%$. Secara keseluruhan media buku dan video variasi latihan ladder drill ini layak digunakan pada peserta ekstrakurikuler sepakbola tingkat sekolah dasar.
\end{abstract}

Kata kunci: pengembangan, ladder drill, sepakbola

\section{PENDAHULUAN}

Olahraga mempunyai peran penting bagi kesehatan. Dengan berolahraga maka kesehatan tubuh akan tetap terjaga. Oleh sebab itu menimbulkan kegemaran / rasa suka untuk tetap berolahraga sangat perlu, karena pada saat sekarang ini banyak sekali hal-hal yang berpengaruh untuk menimbulkan rasa malas dalam berolahraga, sehingga pada zaman sekarang ini diciptakan berbagai macam bentuk permainan olahraga yang menarik yang intinya agar kita mau untuk berolahraga.

Olahraga memiliki tujuan tertentu tergantung pada jenis olahraga yang akan diikuti. Diantaranya olahraga prestasi, olahraga pendidikan, olahraga kesehatan dan kebugaran, olahraga rekreasi, olahraga rehabilitasi, dan olahraga tradisional. Olahraga yang dilakukan dengan tujuan untuk meraih prestasi pada suatu cabang olahraga contohnya olahraga yang diperlombakan seperti sepakbola, voli, basket, tinju, dan lain sebagainya.

Sepakbola merupakan cabang olahraga permainan yang paling popular di dunia. Sepakbola mampu menembus berbagai kalangan masyarakat yang memiliki batas etnis, budaya, dan agama. Oleh karenanya sepakbola telah menjadi bagian nyata di masyarakat. Pertandingan sepakbola adalah pertandingan yang dimainkan oleh 2 (dua) tim yang masing-masing beranggotakan 11 orang. Masing-masing tim mempertahankan gawang dan berusaha menjebol gawang lawan (Luxbacher dalam Ivan Budianto 2015: 4). Kerjasama antar pemain dalam permainan sepakbola sangat membutuhkan kekompakan dan saling mengimbangi satu sama lain. Setiap pemain harus mengeluarkan semua kemampuan yang dimiliki agar dapat menampilkan suatu performa yang baik 
dalam pertandingan. Peran pelatih sangat dominan dalam membentuk atlet menjadi pemain yang professional dan mempunyai teknik, fisik, dan mental bertanding yang tangguh.

Ladder drill atau tangga latihan adalah salah satu alat untuk melatih kelincahan yang berbentuk tangga yang diletakkan di permukaan tanah atau lapangan yang berfungsi untuk melatih otot kaki. Tangga latihan merupakan beberapa alat peraga yang paling umum di seluruh dunia dan alat ini membantu atlet dalam berbagai macam gerakan yang melatih kecepatan dan kelincahan dengan koordinasi kaki yang baik. Latihan ini juga mengajarkan pemain untuk mengambil langkah-langkah yang tepat dengan menggunakan kecepatan dan kelincahan yang dimiliki. Latihan menggunakan tangga latihan merupakan salah satu variasi latihan dari sekian banyak variasi yang ada dalam bentuk latihan fisik disertai keterampilan gerak yang fungsinya melatih kecepatan, kelincahan kaki dan sinkronisasi gerak secara seimbang (Reynolds dalam Firdaus Soffan dkk., 2016).

\section{METODE}

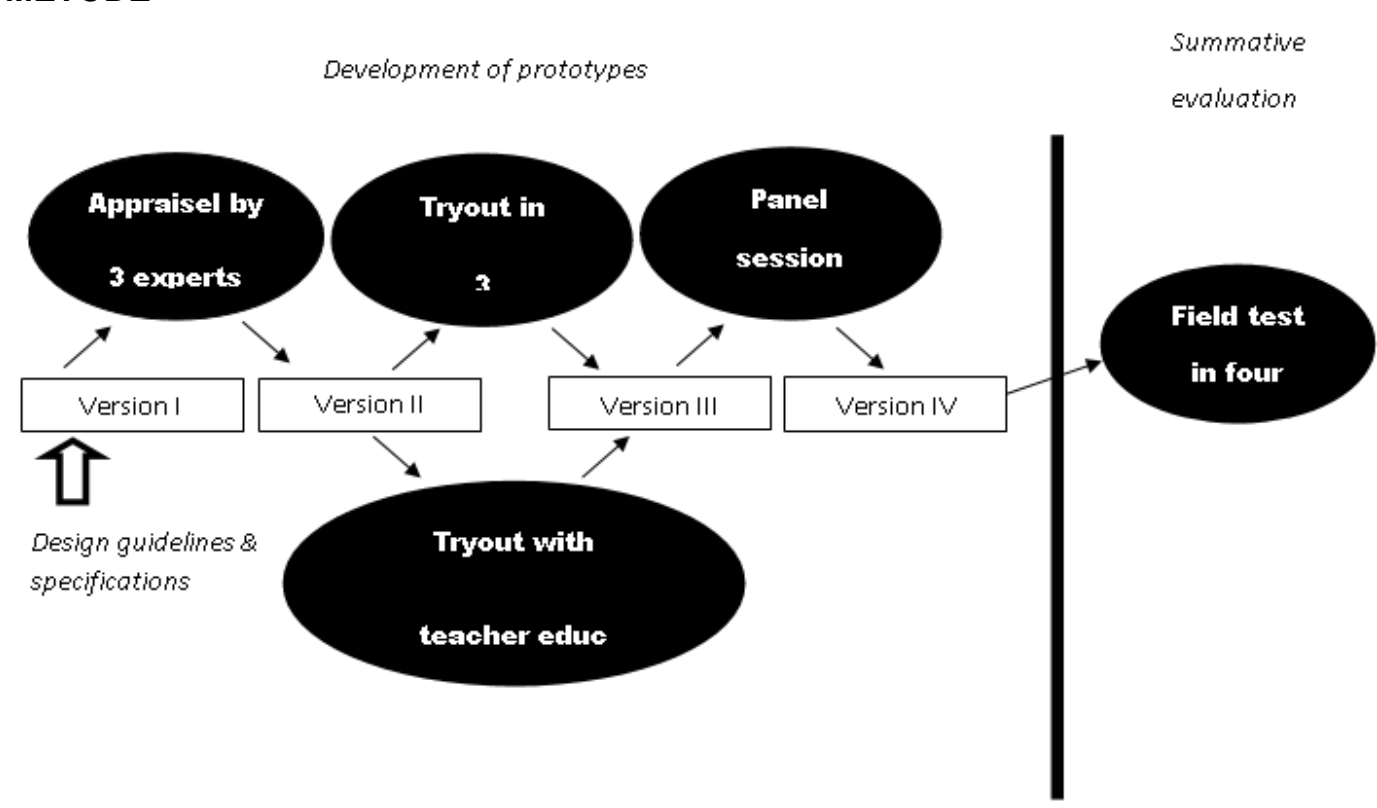

Gambar 1. Desain Penelitian Rancangan

Pembuatan Variasi Latihan Ladder Drill

1. Pengembang membuat sketsa dengan urutan sebagai berikut :

a. Gerakan melompat dari 1 kaki ke 1 kaki.

b. Gerakan melompat dari 2 kaki ke 2 kaki

c. Gerakan melompat dari 1 kaki ke 2 kaki.

d. Gerakan melangkah dari 1 kaki ke 2 kaki.

e. Gerakan melangkah dari 2 kaki ke 2 kaki.
2. Validasi ke 2 ahli materi yaitu ke mantan pesepakbola profesional dan pelatih berlisensi. Kedua ahli materi tersebut memberikan tambahan gerakan-gerakan yang belum ada.

3. Validasi ke ahli media. Ahli media memberi masukan bagaimana cara membuat gambar gerakan ladder drill dan bahasa yang tepat cara melakukan gerakan supaya jelas dan mudah dipahami oleh siswa sekolah dasar. Kemudian karena produk dari penelitian pengembangan ini berupa 
buku paket, maka ahli media memberikan saran variasi latihan ladder drill yang dikembangkan dalam penyusunannya disusun secara sistematis dari variasi yang paling mudah ke variasi yang tersulit sehingga siswa lebih mudah dalam mempelajarinya.

\section{Pengumpulan Data}

1. Peneliti mengembangkan pedoman dan perincian rancangan berupa buku paket. Pedoman berupa buku paket tersebut kemudian dimintakan penilaian dari 3 orang ahli yang bersangkutan. 1 ahli media dan 2 ahli materi yaitu mantan pesepakbola dan pelatih sepakbola. Ada beberapa masukan dari 3 ahli tersebut kemudian dijadikan bahan revisi.

2. Dari hasil revisi diperoleh versi kedua dari paket variasi latihan ladder drill.

3. Dari versi yang kedua ini dilaksanakan seminar dengan menunjukkan rancangan buku yang sudah di validasi oleh 1 ahli media dan 2 ahli materi, seminar dilaksanakan dengan menghadirkan pembimbing dan penguji.

4. Dari masukan seminar tersebut kemudian direvisi dan dihasilkan versi yang ketiga.

5. Dari versi yang ketiga ini di uji cobakan pada peserta ekstrakurikuler sepakbola.

6. Variasi latihan ladder drill di uji cobakan pada peserta ekstrakurikuler sepak bola. Setiap anak melakukan 100 variasi latihan ladder drill. Dari 100 variasi latihan ladder drill yang di uji cobakan pada peserta ekstrakurikuler sepak bola diperoleh berapa gerakan yang bisa dilakukan oleh setiap anak dan hasil akhirnya diperoleh kesimpulan pengembangan variasi latihan ladder drill ini untuk peserta ekstrakurikuler sepakbola di tingkat sekolah dasar masuk dalam kategori baik, cukup, atau kurang. Dari hasil uji coba tersebut kemudian dijadikan sebagai bahan revisi.

7. Dari hasil revisi tersebut dihasilkan versi keempat.

\section{Uji Coba Model}

1. Peserta ekstrakurikuler sepakbola sebanyak 20 siswa diberikan latihan ladder drill 3x seminggu. Setiap sesi peneliti menjelaskan dan memberikan contoh 10 variasi latihan ladder drill. Misalkan pada hari pertama peneliti menjelaskan dan memberikan contoh variasi 1 sampai variasi 10 . Kemudian pada hari kedua peneliti menjelaskan dan memberikan contoh variasi 11 sampai variasi 20 , begitu seterusnya sampai hari ke 10. Ada 100 variasi latihan ladder drill berarti penelitian berlangsung selama 3 minggu lebih.

2. Siswa dibariskan. Kemudian peneliti menjelaskan kepada siswa bahwa nanti setelah pemanasan, peneliti memberikan contoh 10 variasi latihan ladder drill dan siswa memperhatikan. Peneliti menjelaskan bahwa nanti pada saat pelaksanaannya pertamatama siswa dibariskan lurus ke belakang sesuai absen. Kemudian 1 per 1 siswa melakukan variasi latihan ladder drill 1. Dalam melakukan setiap variasi setiap siswa diberikan waktu selama 30 detik. Misalnya apabila sebelum 30 detik siswa nomer absen 1 mampu melakukan variasi latihan ladder drill 1, maka siswa tersebut langsung diinstruksikan berbaris di belakang sendiri dan giliran siswa nomer absen 2 untuk melakukan variasi latihan ladder drill 1. Lalu apabila siswa nomer absen 1 dalam waktu 30 detik tidak mampu melakukan variasi latihan ladder drill 1 , maka siswa tersebut dianggap tidak bisa, kemudian diinstruksikan untuk berbaris di belakang sendiri, lalu giliran siswa nomer absen 2 untuk 
melakukan variasi latihan ladder drill 1. Begitu seterusnya sampai siswa nomer absen 20. Setelah itu siswa nomer absen 1 melakukan variasi latihan ladder drill 2. Begitu seterusnya sampai variasi latihan ladder drill 10. Istirahat setiap siswa dalam melakukan setiap variasi latihan ladder drill adalah 10 menit.

3. Sampai pada hari ke 10 hasil akhirnya dapat diketahui dari 100 variasi latihan ladder drill setiap siswa mampu melakukan berapa variasi latihan.

4. Kemudian dimasukkan ke dalam rumus, lalu dapat disimpulkan apakah variasi latihan ladder drill yang dikembangkan pada tingkat sekolah dasar ini masuk dalam kategori baik, cukup, atau kurang.

\section{Populasi dan Sampel}

Dalam penelitian ini populasi yang akan digunakan adalah seluruh siswa ekstrakurikuler sepakbola di SDN 1 Cluring yang berjumlah 20 siswa. Karena jumlah kurang dari 100 maka sampelnya adalah sampel populasi yaitu 20 siswa peserta ekstrakurikuler sepakbola.

\section{Analisis Data}

Analisis data pada penelitian ini adalah observasi langsung pada percobaan model yang dikembangkan dan selanjutnya dilihat prosentasenya untuk mengetahui perkembangan hasil model yang dikembangkan.

\section{HASIL DAN PEMBAHASAN Hasil Penilaian Para Ahli Pada Buku Paket Versi Pertama}

\section{Ahli Media Pembelajaran}

Penilaian ahli media pembelajaran dilakukan oleh Raup Padillah, M.Pd yang bersangkutan memiliki kriteria sebagai berikut: Dosen Universitas PGRI Banyuwangi yang memiliki kualifikasi Magister Teknologi Pembelajaran. Berdasarkan hasil penilaian dari ahli media pembelajaran dapat dilampirkan sebagai berikut:

Tabel 1. Penilaian Dari Ahli Media Pembelajaran

\begin{tabular}{clc}
\hline No & \multicolumn{1}{c}{ Aspek } & \multicolumn{1}{c}{ Penilaian } \\
\hline 1 & Tingkat kesesuaian isi dengan materi & Sudah sesuai \\
\hline 2 & Gaya penggunaan bahasa & Cukup sederhana \\
\hline 3 & $\begin{array}{l}\text { Kesesuaian penggunaan istilah sesuai } \\
\text { pemahaman anak sekolah dasar }\end{array}$ & Cukup sesuai \\
\hline 4 & Kesesuaian variasi latihan ladder drill & Sudah sesuai \\
\hline 5 & Tingkat kejelasan bahasa & Cukup jelas \\
\hline 6 & $\begin{array}{l}\text { Kemenarikan bahan yang disampaikan melalui } \\
\text { media }\end{array}$ & Cukup menarik \\
\hline 7 & $\begin{array}{l}\text { Kejelasan tulisan yang muncul dalam media yang } \\
\text { dikembangkan }\end{array}$ & Sudah jelas \\
\hline 8 & $\begin{array}{l}\text { Kesesuaian antara gambar dengan materi pelajaran } \\
\text { dalam tampilan media yang dikembangkan }\end{array}$ & Sudah sesuai \\
\hline 9 & $\begin{array}{l}\text { Apakah gambar yang ditampilkan sudah jelas untuk } \\
\text { dipergunakan dalam latihan }\end{array}$ & Sudah jelas \\
\hline 10 & $\begin{array}{l}\text { Apakah media yang dikembangkan sesuai dengan } \\
\text { karakteristik siswa sekolah dasar }\end{array}$ & Cukup sesuai \\
\hline
\end{tabular}




\section{Ahli Pesepakbola Profesional}

Penilaian ahli materi dilakukan oleh Suparno, S.Pd yang bersangkutan merupakan mantan pesepakbola profesional yang telah berhasil membawa Persewangi masuk
Divisi I PSSI untuk pertama kalinya pada tahun 1996/1997 dan beliau adalah guru PJOK di SDN 1 Cluring. Hasil penilaian dari ahli pembelajaran sepakbola sebagai berikut:

Tabel 2. Penilaian Ahli Pesepakbola Profesional

\begin{tabular}{|c|c|c|}
\hline No & Aspek & Penilaian \\
\hline 1 & $\begin{array}{lcrc}\begin{array}{l}\text { Kesesuaian } \\
\text { dikembangkan }\end{array} & \text { media } & \text { pembelajaran } & \text { yang } \\
\text { pembelajaran } & & \text { pencapaian } & \text { tujuan } \\
& & & \end{array}$ & Sudah sesuai \\
\hline 2 & $\begin{array}{l}\text { Kesesuaian materi pembelajaran dengan media } \\
\text { yang dikembangkan }\end{array}$ & Sudah sesuai \\
\hline 3 & $\begin{array}{l}\text { Keterpaduan urutan penyajian materi dengan } \\
\text { prosedur pembelajaran yang diterapkan }\end{array}$ & Sudah sistematis \\
\hline 4 & $\begin{array}{l}\text { Kesesuaian isi materi dengan karakteristik siswa } \\
\text { sekolah dasar }\end{array}$ & Sudah sesuai \\
\hline 5 & $\begin{array}{l}\text { Sistematika atau urutan materi pelajaran yang } \\
\text { disampaikan melalui media }\end{array}$ & Sudah sistematis \\
\hline 6 & $\begin{array}{l}\text { Ketepatan pemilihan strategi yang digunakan dalam } \\
\text { mempelajari bahan }\end{array}$ & Sudah tepat \\
\hline 7 & $\begin{array}{l}\text { Kesederhanaan dan ketepatan penggunaan istilah- } \\
\text { istilah yang digunakan pada penyampaian materi }\end{array}$ & $\begin{array}{l}\text { Sudah sederhana dan } \\
\text { tepat }\end{array}$ \\
\hline 8 & $\begin{array}{l}\text { Adanya kedalaman materi yang disampaikan } \\
\text { melalui media }\end{array}$ & Ada \\
\hline 9 & $\begin{array}{l}\text { Kemenarikan bahan yang disampaikan melalui } \\
\text { media }\end{array}$ & Cukup menarik \\
\hline 10 & $\begin{array}{l}\text { Keefektifan pembelajaran dengan menggunakan } \\
\text { media yang dikembangkan }\end{array}$ & Sudah efektif \\
\hline
\end{tabular}

\section{Pelatih Sepakbola}

Penilaian ahli materi dilakukan oleh Ribut Santoso yang bersangkutan memiliki kriteria sebagai berikut: Pelatih sepakbola yang memiliki kualifikasi Pelatih Sepakbola tingkat $S_{3}$ dan Pelatih Sepakbola Lisensi "C" Nasional. Hasil penilaian dari ahli pembelajaran sepakbola sebagai berikut:

Tabel 3. Penilaian Pelatih Sepakbola

\begin{tabular}{|c|c|c|}
\hline No & Aspek & Penilaian \\
\hline 1 & $\begin{array}{lccc}\text { Kesesuaian } & \text { media } & \text { pembelajaran } & \text { yang } \\
\text { dikembangkan } & \text { dengan } & \text { pencapaian } & \text { tujuan } \\
\text { pembelajaran } & & & \end{array}$ & Sudah sesuai \\
\hline 2 & $\begin{array}{l}\text { Kesesuaian materi pembelajaran dengan media } \\
\text { yang dikembangkan }\end{array}$ & Sudah sesuai \\
\hline 3 & $\begin{array}{l}\text { Keterpaduan urutan penyajian materi dengan } \\
\text { prosedur pembelajaran yang diterapkan }\end{array}$ & Sudah sistematis \\
\hline
\end{tabular}




\begin{tabular}{|c|c|c|}
\hline 4 & $\begin{array}{l}\text { Kesesuaian isi materi dengan karakteristik siswa } \\
\text { sekolah dasar }\end{array}$ & Sudah sesuai \\
\hline 5 & $\begin{array}{l}\text { Sistematika atau urutan materi pelajaran yang } \\
\text { disampaikan melalui media }\end{array}$ & Sudah sistematis \\
\hline 6 & $\begin{array}{l}\text { Ketepatan pemilihan strategi yang digunakan dalam } \\
\text { mempelajari bahan }\end{array}$ & Sudah tepat \\
\hline 7 & $\begin{array}{l}\text { Kesederhanaan dan ketepatan penggunaan istilah- } \\
\text { istilah yang digunakan pada penyampaian materi }\end{array}$ & $\begin{array}{l}\text { Sudah sederhana dan } \\
\text { tepat }\end{array}$ \\
\hline 8 & $\begin{array}{l}\text { Adanya kedalaman materi yang disampaikan } \\
\text { melalui media }\end{array}$ & Cukup \\
\hline 9 & $\begin{array}{l}\text { Kemenarikan bahan yang disampaikan melalui } \\
\text { media }\end{array}$ & Sudah menarik \\
\hline 10 & $\begin{array}{l}\text { Keefektifan pembelajaran dengan menggunakan } \\
\text { media yang dikembangkan }\end{array}$ & Sudah efektif \\
\hline
\end{tabular}

\section{Proses Pemanfaatan Buku Paket Versi Kedua}

Peneliti menjelaskan kepada siswa bahwa nanti setelah pemanasan, peneliti memberikan contoh 10 variasi latihan ladder drill dan siswa memperhatikan. Peneliti menjelaskan bahwa nanti pada saat pelaksanaannya pertama-tama siswa dibariskan lurus ke belakang sesuai absen. Kemudian 1 per 1 siswa melakukan variasi latihan ladder drill 1. Dalam melakukan setiap variasi setiap siswa diberikan waktu selama 30 detik. Misalnya apabila sebelum 30 detik siswa nomer absen 1 mampu melakukan variasi latihan ladder drill 1, maka siswa tersebut langsung diinstruksikan berbaris di belakang sendiri dan giliran siswa nomer absen 2 untuk melakukan variasi latihan ladder drill 1. Lalu apabila siswa nomer absen 1 dalam waktu 30 detik tidak mampu melakukan variasi latihan ladder drill 1, maka siswa tersebut dianggap tidak bisa, kemudian diinstruksikan untuk berbaris di belakang sendiri, lalu giliran siswa nomer absen 2 untuk melakukan variasi latihan ladder drill 1. Begitu seterusnya sampai siswa nomer absen 20. Setelah itu siswa nomer absen 1 melakukan variasi latihan ladder drill 2. Begitu seterusnya sampai variasi latihan ladder drill 10. Istirahat setiap siswa dalam melakukan setiap variasi latihan ladder drill adalah 10 menit. Sampai pada hari ke 10 hasil akhirnya dapat diketahui dari 100 variasi latihan ladder drill setiap siswa mampu melakukan berapa variasi latihan.

\section{Uji Coba Variasi Latihan Ladder Drill}

Berikut rincian hasil uji coba variasi latihan ladder drill :

Tabel 4. Hasil Uji Coba Pada Peserta Ekstrakurikuler

\begin{tabular}{cccc}
\hline No & Subyek & Hasil & Kategori \\
\hline $\mathbf{1}$ & S1 & 97 & Baik \\
\hline $\mathbf{2}$ & S2 & 98 & Baik \\
\hline $\mathbf{3}$ & S3 & 96 & Baik \\
\hline $\mathbf{4}$ & S4 & 95 & Baik \\
\hline $\mathbf{5}$ & S5 & 100 & Baik \\
\hline $\mathbf{6}$ & S6 & 95 & Baik \\
\hline $\mathbf{7}$ & S7 & 98 & Baik \\
\hline $\mathbf{8}$ & S8 & 99 & Baik \\
\hline
\end{tabular}




\begin{tabular}{cccc}
\hline 9 & $S 9$ & 94 & Baik \\
\hline 10 & $S 10$ & 95 & Baik \\
\hline 11 & $S 11$ & 92 & Baik \\
\hline 12 & $S 12$ & 94 & Baik \\
\hline 13 & $S 13$ & 93 & Baik \\
\hline 14 & $S 14$ & 98 & Baik \\
\hline 15 & $S 15$ & 95 & Baik \\
\hline 16 & $S 16$ & 94 & Baik \\
\hline 17 & $S 17$ & 91 & Baik \\
\hline 18 & $S 18$ & 98 & Baik \\
\hline 19 & $S 19$ & 93 & Baik \\
\hline 20 & $S 20$ & 100 & Baik \\
\hline
\end{tabular}

Dari hasil perhitungan kategori variasi latihan ladder drill yaitu $96 \%$, maka dapat disimpulkan bahwa paket variasi latihan ladder drill dinyatakan sangat layak untuk diterapkan pada peserta ekstrakurikuler sepakbola tingkat sekolah dasar.

\section{Seminar Produk Pengembangan Versi Ketiga}

Untuk menguji kelayakan buku paket variasi latihan ladder drill ini dilakukan seminar tertutup dengan beberapa ahli, dosen dan rekan-rekan sejawat pada tanggal 28 Mei 2018. Dari hasil seminar tersebut diperoleh beberapa hal yang perlu diperbaiki, yaitu:

a. 100 variasi latihan ladder drill ini saat diujicobakan kepada siswa jangan langsung semuanya, karena nanti siswa akan capek dan daya tangkap siswa terhadap setiap gerakan akan kurang maksimal. Maka dari itu dalam proses uji coba terhadap siswa, peneliti mengujicobakan 10 variasi 10 variasi pada setiap pelaksanaannya. Pelaksanaannya 1 minggu $3 x$. Jadi penelitian berlangsung selama 3 minggu lebih.

b. Kesempatan mencoba jangan Cuma 1x. Jadi dalam melakukan setiap variasi, siswa diberikan waktu selama 30 detik. Apabila dalam kesempatan pertama siswa gagal, maka diberikan kesempatan mencoba lagi sampai batas waktu 30 detik. Apabila dalam waktu 30 detik siswa tersebut masih tidak mampu, berarti siswa tersebut dianggap tidak mampu melakukan variasi latihan ladder drill pada nomer tersebut.

\section{Klasifikasi Hasil Pengembangan Variasi Latihan Latihan Ladder Drill}

Tabel 5. Klasifikasi Hasil Pengembangan

\begin{tabular}{ccc}
\hline No & Variasi Latihan Ladder Drill & Klasifikasi \\
\hline 1 & Variasi $1-40$ & Sangat mudah \\
\hline 2 & Variasi $41-52$ & Mudah \\
\hline 3 & Variasi $53-74$ & Sedang \\
\hline 4 & Variasi $75-89$ & Sulit \\
\hline 5 & Variasi $90-100$ & Sangat sulit \\
\hline
\end{tabular}




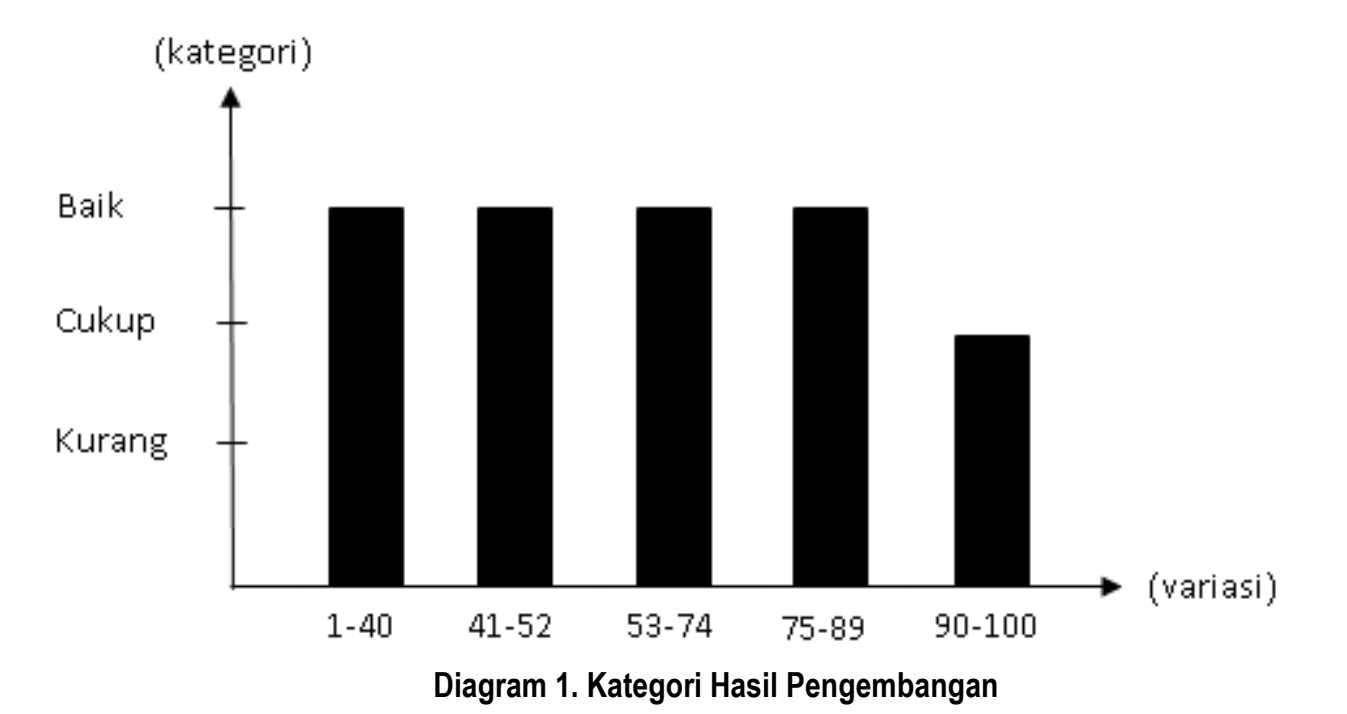

Dari hasil penelitian dilihat dari latihan ladder drill didapat variasi latihan yang paling banyak mampu dilakukan siswa yaitu variasi 1-40 dengan kategori baik, variasi 41-52 dengan kategori baik, variasi 53-74 dengan kategori baik, dan variasi 75-89 dengan kategori baik.

\section{KESIMPULAN}

Berdasarkan hasil penelitian dan pengembangan Buku Variasi Latihan Ladder Drill, berikut ini dirumuskan beberapa simpulan tentang produk yang didasarkan pada rumusan masalah dan pertanyaan penelitian:

a. Pembuatan produk diawali dengan tahap mengembangkan variasi latihan ladder drill yang sebelumnya belum pernah ada. Perancangan produk dimulai dengan membuat rancangan di kertas HVS, setelah tercipta sekian banyak variasi kemudian di validasi pada ahli materi (mantan pesepakbola profesional dan pelatih sepakbola berlisensi). Setelah itu di validasi lagi ke ahli media (Magister Teknologi Pendidikan). Kemudian editing gambar di buku melalui Paint, spesifikasi produk dengan ukuran 105 x $148 \mathrm{~mm}$ dengan jumlah halaman 100.

b. Tingkat kelayakan Variasi Latihan Ladder Drill pada peserta ekstrakurikuler sepakbola tingkat sekolah dasar ini berdasarkan rumus (Arikunto dalam Tika Marita, 2013: 29) sebesar 96\%. Secara keseluruhan media buku dan video variasi latihan ladder drill ini layak digunakan pada peserta ekstrakurikuler sepakbola tingkat sekolah dasar. Penelitian pengembangan ini dapat digunakan referensi oleh siswa yang ingin mempelajari variasi-variasi latihan ladder drill.

\section{DAFTAR PUSTAKA}

Aji, GP. 2016. Pengembangan alat ladder untuk latihan koordinasi, kelincahan dan power [skripsi]. Yogyakarta (ID): Universitas Negeri Yogyakarta

Aniq, R. 2012. Pengaruh permainan tradisional gobag sodor terhadap tingkat empati anak [skripsi]. Malang (ID): Universitas Islam Negeri Maulana Malik Ibrahim Malang

Budianto I. 2015. Sumbangan kecerdasan IQ, keseimbangan, dan kecepatan reaksi terhadap kemampuan kiper dalam mengantisipasi arah bola [skripsi]. Semarang (ID): Universitas Negeri Semarang 
Farhanto, G. 2016. Pengembangan paket pelatihan keterampilan taktik bertanding bola voli bagi siswa sekolah menengah [tesis]. Malang (ID): IKIP Budi Utomo Malang

Hadi, FS., dkk. 2016. Pengaruh latihan ladder drills terhadap peningkatan kelincahan siswa u-17 di persatuan sepakbola Jajag Kabupaten Banyuwangi. Jurnal Pendidikan Jasmani. Vol.26(1): 213-228

Ismoyo, F. 2014. Pengaruh latihan variasi speed ladder drill terhadap kemampuan dribbling, kelincahan, dan koordinasi siswa SSB Angkatan Muda Tridadi kelompok umur 11-12 tahun [skripsi]. Yogyakarta (ID): Universitas Negeri Yogyakarta

Juliyanto, OD. 2016. Pengaruh latihan ladder drill icky shuffle terhadap peningkatan kecepatan. Jurnal Kesehatan. Vol.7(3): 45-52

Naufal, MH. 2016. Pengaruh latihan dodging run dan ladder drill terhadap kelincahan kaki atlet bulutangkis putra usia 12-13 tahun PB. Harapan Jaya Kabupaten Magelang [skripsi]. Yogyakarta (ID): Universitas Negeri Yogyakarta

Pramukti, T. dan Junaidi, S. 2015. Pengaruh latihan ladder drill dan latihan abc run terhadap peningkatan kecepatan pemanjatan jalur speed atlet panjat tebing FPTI Kota Magelang. Journal of Sport Sciences and Fitness. Vol.4(1): 40-43

Prasetyo, J. 2017. Kontribusi kekuatan otot tungkai, keseimbangan, dan kecepatan terhadap kemampuan tendangan sabit pada siswa ekstrakurikuler tapak suci di SMP Muhammadiyah 1 Gadingrejo Pringsewu [skripsi]. Bandar Lampung (ID): Universitas Lampung
Rosidi, S. 2016. Penelitian Terapan Profesi Pendidikan. Malang: Nams

Suci, RO. 2015. Hubungan antara kekuatan otot tungkai kelincahan dan koordinasi mata-kaki terhadap keterampilan menggiring bola peserta ekstrakurikuler futsal SMP Negeri 2 Banguntapan Kabupaten Bantul Provinsi Yogyakarta [skripsi]. Yogyakarta (ID): Universitas Yogyakarta 